\title{
De narizes extraídos por Machado: eugenias raciais, traços faciais e teorias psiquiátricas no Brasil oitocentista
}

\author{
Alexandre de Carvalho Castro*1
}

$O$ objetivo deste artigo foi analisar as relações dialógicas entre o eugenismo de Alphonse Bué em "Le nez, l'être dévoile par sa forme" (1872) e a narrativa literária de Machado de Assis, a partir do conto "O segredo do bonzo” (1882). Assim, segundo a perspectiva dialógica de Mikhail Bakhtin, verificou-se que Machado de Assis criticou, por intermédio de sátiras e paródias, a psiquiatria de viés eugenista que buscava numa suposta morfologia de traços simiescos - baseando-se no nariz, no caso de Alphonse Bué - a etiologia de condutas sociais.

Palavras-chave: Eugenismo, racismo, Alphonse Bué, Machado de Assis

*1 Centro Federal de Educação Tecnológica Celso Suckow da Fonseca (Rio de Janeiro, $\mathrm{RJ}, \mathrm{Br}$ ). 


\section{Introdução}

Nas últimas décadas do século XIX, principalmente na Europa, muitas questões referentes às ciências da saúde passaram por reformulações em decorrência da emergência das teorias evolutivas. Assim, a medição de características cranianas, o estudo do tamanho de cérebros, a análise de tipologias anatômicas, e a estigmatização de traços sociais formaram um conjunto de medidas socioantropométricas que implicava o ordenamento de grupos raciais (Gould, 1991).

Esses estudos se reforçavam mutuamente e causavam, por sua vez, forte impacto nas sociedades oitocentistas, pois as conclusões corolárias a tais metodologias apontavam índices de criminalidade e degeneração vinculados geralmente, mesmo que dentre outros, a negros e seus descendentes. Dessa forma, conceitos como "eugenia" - cunhado por Francis Galton (1822-1911) para descrever o estudo sobre qualidades raciais - acabaram por emergir nesse extenso cenário que tanto identificava traços tidos como simiescos, de modo evolutivamente inferior, quanto inferia que a raça negra estava em posição de subordinação diante da raça branca.

Essa tendência da ciência em fins do oitocentos, assim como sua influência no Brasil, é um fato amplamente documentado e recorrentemente referido na história da psiquiatria, tratando-se, sem dúvida, de uma questão já amplamente debatida e pesquisada (Mansanera \& Silva, 2000). O ponto de interesse para este artigo, no entanto, é que conquanto alguns teóricos dessa vertente sejam amplamente conhecidos, há outros que permanecem no anonimato, muito embora também tenham ensejado análises e interessantes assertivas no meio intelectual brasileiro da época.

Esse foi particularmente o caso de Hector Joseph Bouvier - conhecido como Alphonse Bué — médico francês apresentado em suas obras como Membro da "Presse Scientifique" e da "Société Française d'hygiène" (cf. Bué, 1894). Ele publicou uma série de livros, ${ }^{1}$ e até se tornou mais comentado pelos

${ }^{1}$ No site da WorldCat (www.worldcat.org/), uma rede virtual de conteúdo e serviços de diversas bibliotecas universitárias, estão listados vários livros na base de dados sob o descritor "Hector Joseph Alphonse Bué". Dentre os tais, é possível destacar: La Main, essai physiologique et psychologique (1871); Le Nez, l'être dévoilé par sa forme (1872); Guérison d'une somnanbule racontée par elle-même dans son som meil magnétique (1875); La Vie et la santé, ou la Médecine est-elle une science? (1882); Le magnétisme curatif: manuel technique avec un portrait de Mesmer (1893); Le magnétisme curatif: psycho-physiologie (1894). 


\section{HISTÓRIA DA PSIQUIATRIA}

estudos psiquiátricos acerca do magnetismo humano do que propriamente pela questão eugenista. Tanto que, numa investigação sobre abordagens psiquiátricas no ambiente cultural francês, de fins do século XIX, Alphonse Bué foi referido como médico militar que, por efetivamente acreditar no potencial terapêutico do magnetismo, escreveu ensaios sobre o tema no período compreendido entre 1870 e 1900 (Finn, 2009). Tal ênfase dos seus últimos livros não deve causar estranheza, pois investigações históricas sobre a época mostram que a reabilitação do hipnotismo como método para tratamento da histeria, por intermédio de Jean Martin Charcot (1825-1893) a partir de 1870s, promoveu na França um movimento eventualmente caracterizado como neomesmerismo. Nesse contexto, até Alfred Binet (1857-1911) - que posteriormente se tornaria muito mais citado pelos estudos sobre inteligência - chegou a escrever, também com base em Franz Anton Mesmer (1734-1815), um livro sobre magnetismo animal (Plas, 2012).

Ora, como a França exercia grande influência cultural em relação ao Brasil, é interessante destacar que a produção psiquiátrica de Alphonse Bué não passou despercebida na época, e especificamente três de suas obras tiveram repercussão em terras brasileiras: "Le nez, l'être dévoile par sa forme" (1872); "Le magnétisme curatif: manuel technique (avec un portrait de Mesmer)" (1893); e "Le magnétisme curatif: psycho-physiologie (hypnotisme, somnambulisme, fascination, suggestion mentale, clairvoyance, loi phénoménale de la vie)" (1894). Esses últimos dois livros sobre magnetismo, vale a pena ressaltar, mantinham, em fins do séc. XIX, status de obra científica e aludiam, em meio aos vários estudiosos citados, a autores do porte de Charcot, Lombroso e Binet. Porém, tais escritos acadêmicos se tornaram, mais tarde, referência religiosa, ${ }^{2}$ comprovando o fato de que um modelo inicialmente tido

${ }^{2}$ No site da Biblioteca Virtual Espírita (http://bvespirita.com/), na busca de livros por autor, são indicados, na letra "A", os dois volumes sobre "Magnetismo curativo", cuja edição apresenta o autor também com o nome de Alphonse Bouvier (além de Alphonse Bué). A tradução em português do volume II (que corresponde a Bué, Alphonse. Le magnétisme curatif: psycho-physiologie. Paris: Chamuel éditeur, 1894) não inclui, no entanto, uma nota biográfica sobre Durand de Gros, disponível no original em francês. No site "The Internet Archive", que viabiliza o acesso a coleções digitalizadas é permitido acessar dentre o material disponibilizado pela "University of California", em formato digital, o "Boletim das Bibliothecas e Archivos Nacionaes. Coimbra, Imprensa da Universidade. 1906" (cf. https://archive.org/details/boletimdasbibli03nacigoog), onde — num registro feito por Hippolyte Garnier, na condição de quem desejava listar nesse importante catálogo as edições que publicara no ano anterior — é possível constatar que tal apropriação religiosa da obra de Bué, no Brasil, remonta ao início do século XX: “Alphonse Bué: Magnetismo curador. Manual technico, Vade mecum do estudante magnetizador, 2 volumes. Tradução autorizada pelo autor e publicada sob os auspícios da Federação Espírita Brasileira, 1905. Paris, typographia H. Garnier.” (cf. Garnier, 1906, p. 204). 
como científico, mas posteriormente ultrapassado da perspectiva do desenvolvimento da pesquisa, tende a sobreviver em opiniões do senso comum sobre a ciência (Camargo Jr., 2007).

Todavia, a despeito da contribuição de Bué ao neomesmerismo, o que interessa mais objetivamente a este estudo é a repercussão de seu livro anterior, de tendência eugenista, publicado em 1872. A razão dessa escolha recai sobre o fato de que Machado de Assis desenvolveu interessantes considerações em torno das proposições de Bué. E, além disso, o estudo se justifica por investigar um tema acerca do qual não há praticamente nada publicado, nem do ponto de vista da história da psiquiatria, nem da perspectiva dos comentadores machadianos. Assim, em função do que foi exposto até aqui, o objetivo deste artigo consiste em analisar as relações dialógicas entre o eugenismo de Alphonse Bué em 'Le nez, l'être dévoile par sa forme” e a narrativa literária de Machado de Assis.

\section{Metodologia}

Tendo em vista esse cenário, e a fim de justificar as opções metodológicas adotadas, convém reiterar que o foco deste artigo remete ao dialogismo da crítica feita por Machado de Assis a um argumento que buscava numa suposta morfologia de traços simiescos - tendo por base o nariz, no caso dessa obra de Alphonse Bué - a etiologia de condutas sociais.

Destarte, como o método de trabalho assumiu procedimentos típicos de análises discursivas, foi adotado o referencial teórico-metodológico de Bakhtin (2004), por indicar que os textos, ao serem analisados, devem ser situados em seu contexto sociocultural, mediante a investigação das práticas discursivas nas quais emergiram. E nessas alusões não só à subjetividade, mas também à intersubjetividade, as proposições machadianas não devem ser interpretadas em si mesmas, mas em função da relação dialógica que mantinham com outros textos que igualmente circulavam, ganhavam densidade e eram comentados no meio social. Meio esse que incorporava, na Belle Époque carioca, tanto o verniz da erudição francesa, como referência cultural, quanto a dimensão racista da eugenia enquanto fundamento científico das ciências da saúde.

O trabalho de investigação, portanto, foi centrado nas fontes primárias disponíveis conforme a seguinte discriminação:

a) A obra em francês de Alphonse Bué foi examinada conforme disponibilizada no site da Gallica (http://gallica.bnf.fr/), que é o acervo digital da Biblioteca Nacional da França, onde é possível encontrar com os descritores para autor "Bué, Hector Joseph, dit Alphonse" e/ou "Bué, Alphonse (1829-...)" cinco de seus livros, digitalizados; 


\section{HISTÓRIA DA PSIQUIATRIA}

b) o texto "Revelações physiologicas: o nariz" (que é a tradução em português de "Le nez, l'être dévoile par sa forme"), publicado originalmente em "A Estação", no período de 31 de dezembro de 1880 a 15 de julho de 1881, foi consultado em microfilme na seção de obras raras da Biblioteca Nacional, mas atualmente também se encontra disponível em formato digital no site da instituição;

c) os romances, crônicas e contos de Machado de Assis foram analisados mediante consulta ao Espaço Machado de Assis (http://www.machadodeassis.org.br/), produzido pela Academia Brasileira de Letras para destinar-se à pesquisa e à difusão do universo machadiano;

d) algumas análises desta pesquisa, contudo, também lançaram mão do site organizado por Claudio Weber Abramo (http://www.uol.com.br/machadodeassis/), que consiste na única coleção completa com o texto integral dos contos de Machado de Assis.

Nesse sentido, em função de tais fontes, uma palavra deve ser dada em relação ao modo como as citações da obra machadiana foram feitas ao longo do artigo. Pois, já que muitos textos foram consultados em formato digital, na maioria das vezes não foi referida a indicação da paginação, mas apenas o nome do conto, ou livro, e a data da publicação original.

\section{Relações dialógicas}

Machado de Assis trabalhou na revista "A Estação: Jornal Illustrado para a Família", onde atuou ativamente como editor a partir da comunicação da edição de 30 de dezembro de 1879: "a nossa parte litteraria vai ser ampliada e soffrer diversos melhoramentos que a tornará um verdadeiro jornal litterario" (Editorial, 1879, p. 223).

Ora, "A Estação" era uma revista oitocentista feminina que dava grande destaque para a moda, tendo como público leitor as famílias que formavam os grupos sociais mais ricos e letrados do país (Teixeira, 2008). Muito sofisticada, impressa na Europa e produzida conforme os padrões e estilos parisienses, a publicação passou a elaborar no Brasil, contudo, esse suplemento literário onde Machado publicou o texto "Revelações physiologicas: o nariz" (com base em Bué [1872], através da adaptação em cinco partes dos originalmente dez capítulos do livro). Dessa forma, espaçadamente nas edições de 31 de dezembro de 1880 (sob o título "Relações physiologicas: physiognomonia"), 15 de janeiro de 1881, 15 de março de 1881, 31 de março de 1881 e 15 de julho de 1881, tal iniciativa tornou acessível o pensamento desse psiquiatra parisiense para leitores brasileiros.

A leitura do texto evidencia uma argumentação típica da época, mas marcada por algumas peculiaridades. A partir da premissa do nariz como característica essencialmente humana, uma vez que os símios não o possuem, Alphonse Bué procurou 
mostrar que a forma do nariz indicava graus evolutivos. Sua lógica era que pessoas com narizes mais achatados estavam próximas do focinho animal, e aquelas com perfil mais delineado apresentavam condição superior.

Consequentemente, e dentro de uma tradição psiquiátrica onde características fisiológicas eram interpretadas como base do comportamento social, apontou também que diferentes tipos de nariz correspondiam a distintas condições psicológicas. O nariz podia dar conta inclusive das patologias psíquicas:

Para que haja harmonia n'um rosto, é necessário que a distancia tomada do alto da testa ás sobrancelhas, e a que vae da base do nariz á extremidade do queixo seja eguaes entre si, e eguaes ao mesmo tempo á distancia que medeia entre as sobrancelhas e a base do nariz. (...) A estupidez e a loucura proveem sempre da desproporção dessas distancias. (Bué, 15 jul. 1881, p. 146)

Nesse sentido, o autor problematizou a questão se todos os homens têm nariz, citando um provérbio em latim que diz que isso não é dado a todos — Non cuique datum est habere nasum. Ora, esse epigrama ("nem todo mundo é dotado de um nariz"), atribuído a Marcus Valerius Martialis (escritor romano do I século d.C.), é geralmente interpretado no sentido de que não é característica comum ter sensibilidade e bom gosto. Para Bué, contudo, a ideia da citação consistiu em enfatizar que nem todos os narizes eram, de fato, perfeitamente delineados. Assim, insistiu que homens inferiores tinham a fronte deprimida, com o nariz como que a se derramar no rosto, comprovando a profunda diferença entre os tipos selvagens e o rosto do homem inteligente e superior. Sua perspectiva eugenista foi a de mostrar que alguns não tinham efetivamente nariz, mas algo saliente próximo à animalidade, distinção que configurava animais-homens e homens-animais. Uma diferença, aliás, gravada na forma exterior. Sobretudo porque no perfil dos homens inferiores havia a inclinação, as curvas, as inflexões do focinho do irracional; mas no perfil majestoso do homem elevado, inteligente e moral havia as linhas nítidas e puras do verdadeiro nariz humano. E em dado ponto do argumento, também foi ressaltado:

Ainda melhor seria si vos fosse dado ir explorar algumas das regiões selvagens da Africa equatorial, da Laponia ou da Australia: porque vendo esses homens primitivos, de feições mal esboçadas, não hesitareis mais um só instante em concordar commigo que esse nariz, esse verdadeiro nariz de que eu quis fallar dizendo que as suas linhas correctas e puras constituem o perfil humano, não é tão commum como se pensa. (Bué, 15 mar. 1881, p. 50)

E Machado de Assis, ao que parece, aceitou o convite - aparentemente feito por ele mesmo, em uma adaptação que, nesse ponto do artigo, extrapolou parodicamente o original de Bué (1872) — indo ver narizes das regiões selvagens da cidade de Fuchéu, capital do reino de Bungo, onde os tais se apresentavam inchados. 


\section{HISTÓRIA DA PSIQUIATRIA}

Realmente, o conto "O segredo do bonzo" (1882) mantém interessante relação dialógica com o texto eugenista de Alphonse Bué. Tal constatação, inclusive, é a premissa básica deste artigo. No entanto, convém destacar que ao contrário de muitos críticos do eugenismo, a perspectiva de diálogo desenvolvida por Machado não adquiriu caráter objetivo, mas preponderantemente satírico.

A concepção machadiana de estrutura narrativa e procedimento linguístico paródico abria um caminho engajado com os problemas sociais porque a sátira destruía e invertia os valores enrijecidos na ótica dominante, preparando também eventuais momentos de transformação. Ou seja, essa postura frente à linguagem — assumida por Machado (Rego, 1989) - que privilegiava a paródia, a sátira e a ironia, igualmente revelava a face abominável da realidade circundante e provocava a crítica do sistema através da inversão de valores.

As opções dialógicas de Machado não deixam dúvidas quanto ao seu interesse de instalar uma ruptura com o discurso científico-psiquiátrico de fins do século XIX através da desconstrução crítico-satírica do mundo psi. Vide principalmente suas críticas, por meio do mesmo procedimento paródico, aos conceitos de monomania de Jean Étienne Dominique Esquirol (1772-1840), e memória como fato biológico de Théodule Ribot (1839-1916); respectivamente nos contos "O alienista" (1881) e "O lapso" (1883).

Em "O segredo do bonzo" (1882) a referência irônica também é evidente, já que a palavra "bonzo", de origem oriental e incorporada posteriormente ao português, aludia, na ocasião em que o texto foi escrito, tanto a monge budista quanto a uma pessoa falsa ou fingida (Losso, 2008). Além disso, a caracterização do conto como um capítulo inédito do livro de Fernão Mendes Pinto publicado em 1614 "Peregrinação" - também insinuava a controvérsia e a ironia já que esse autor era tido na época como descaradamente mentiroso, a tal ponto de ser referido em trocadilho: Fernão! Mentes? Minto! (Vicente, 2010). O ponto em questão para Machado, então, era o do engano e da dissimulação. Dissimulação essa, aliás, que ganhou maior destaque quando ele organizou o material de "O segredo do bonzo" (originalmente publicado na "Gazeta de Notícias") para publicá-lo junto com outras histórias, no mesmo ano, na coletânea de contos "Papéis avulsos" (1882). Especialmente porque subscreveu uma "nota do autor" esclarecedora: "O bonzo do meu escrito chama-se Pomada, e pomadistas os seus sectários. Pomada e pomadista são locuções familiares da nossa terra: é o nome local do charlatão e do charlatanismo".

A narrativa tem início com o narrador - supostamente Fernão Mendes Pinto - e seu companheiro, Diogo Meireles, passeando pela cidade e constantemente se deparando com ajuntamentos. No primeiro deles um orador foi aclamado pelas multidões por ter descoberto a origem dos grilos, e no outro, o mesmo se deu com quem discorria sobre o princípio da vida futura. Aplausos e mais aplausos aos festejados oradores. As alusões ao pano de fundo do evolucionismo - investigações 
sobre a origem, ou sobre desdobramentos da vida futura - eram, no entanto, explícitas, conquanto hilárias, pois as explicações etiológicas remetiam às folhas dos coqueiros, às conjunções da lua nova e ao sangue das vacas.

Os personagens não consideraram nem racional nem crível nenhum argumento dessas teorias e se interessaram em saber a razão de ser das novas doutrinas. Acabaram assim por descobrir que a procedência dos disparatados ensinamentos derivava do tal Bonzo Pomada do título do conto, defensor da seguinte tese: "se uma coisa pode existir na opinião, sem existir na realidade, e existir na realidade, sem existir na opinião, a conclusão é que das duas existências paralelas a única necessária é a da opinião, não a da realidade, que é apenas conveniente."

Diogo Meireles, apresentado por Machado como alguém que — semelhantemente a Bué — "ocupava-se no exercício da medicina, que estudara convenientemente, e em que era exímio", resolveu então incutir uma ideia no ânimo da multidão. Passou a propor a substituição de narizes inchados e disformes por outros, de natureza metafísica. Alguns filósofos de Bungo admitiram os bons fundamentos da proposta "visto não ser o homem todo outra coisa mais do que um produto da idealidade transcendental". Assim, o médico passou a desnarigar os habitantes da cidade fingindo colher em uma caixa narizes metafísicos para aplicá-los nos rostos vazios, obtendo grande efeito, pois "olhavam uns para os outros, e não viam nada no lugar do órgão cortado; mas, certos e certíssimos de que ali estava o órgão substituto, e que este era inacessível aos sentidos humanos, não se davam por defraudados, e tornavam aos seus ofícios".

Machado de Assis ironizou dessa forma o eugenismo de Bué considerando-o como teoria que expressava uma opinião falsa, sem indicar fatos efetivamente existentes na realidade. O tal nariz elevado, superior e essencializado - nariz que, segundo o título do livro de Bué, por sua forma revelava a condição do ser — não passava de um nariz metafísico. E, assim, a ideia de que nem todos os homens têm narizes configurou-se, no conto machadiano, como objeto de risível paródia. ${ }^{3}$

Muito embora em "O segredo do bonzo" — publicado tanto em "A Gazeta de Notícias" (1882) quanto no livro "Papéis avulsos" (1882) — Machado

${ }^{3}$ França (2007) argumenta a favor de uma relação de intertextualidade entre esse conto e uma história contada por Slawkenbergius, personagem de Laurence Sterne, no livro "The Life and Opinions of Tristram Shandy", publicado originalmente em nove volumes no período entre 1759 e 1767. No entanto, embora a cidade de Strasburg tenha lidado com alguém que tinha um nariz colossal (no livro de Sterne), a narrativa de Machado de Assis segue ordem totalmente diversa no episódio do Reino de Bungo. Além disso, as caracterizações médicas e evolucionistas de "O segredo do bonzo" mostram que a dinâmica dialógica se estabeleceu preponderantemente em relação mesmo a Alphonse Bué, e não a Sterne (1998). 


\section{HISTÓRIA DA PSIQUIATRIA}

tenha dialogado mais diretamente com "Le nez, l'être dévoile par sa forme" (1872), ele igualmente se referiu ao nariz superior teorizado por Bué em outros momentos. Numa crônica de 5 de abril de 1888, por exemplo, falou sobre um "modo de persuadir ao homem a alta linhagem de seu nariz" (Machado de Assis, 1990, p. 36).

O que se tornou um mote para a paródia machadiana, entretanto, foi a ênfase do eugenista na ausência de narizes: "E si quereis ser bem representados, bem governados, lembrai-vos sempre isto: desconfiae dos sujeitos que não teem nariz." (Bué, 31 dez. 1880, p. 262). Publicado um pouco depois de "O segredo do bonzo", o conto "Papéis velhos" (1883) igualmente indica a perda do nariz: "Imaginai um soldado a quem uma bala levasse o nariz, e que, acabada a batalha, fosse procurar no campo o desgraçado apêndice. Suponhamos que o acha entre um grupo de braços e pernas; pega dele, levanta-o entre os dedos — mira-o, examina-o, é o seu próprio... Mas é um nariz ou um cadáver de nariz?"

Ainda nesse mesmo ano em que publicou "Papéis velhos", Machado voltou a relacionar a ponta do nariz e a metafísica, o que possivelmente mostra como o tema originado na crítica a Bué, foi se desenvolvendo por outros caminhos. De fato, em "A ideia do Ezequiel Maia" (1883) apareceu um personagem cuja caracterização foi feita com ênfase — "era idealista" — pois ao focar o nariz perdia a percepção da concretude social. Daí a explicação do narrador: "Depois de largo cogitar, achou Ezequiel um meio: abstrair-se pelo nariz. Consistia em fincar os olhos na extremidade do nariz, à maneira do faquir, embotando a sensibilidade ao ponto de perder toda a consciência do mundo exterior."4

\section{Conclusão}

O objetivo deste artigo consistiu em analisar as relações dialógicas entre a obra eugenista "Le nez, l'être dévoile par sa forme", de Alphonse Bué, e a produção literária de Machado de Assis. Dessa forma, mediante o exame de fontes primárias disponíveis em acervos digitalizados, verificou-se que a crítica machadiana adotou contornos paródicos e satíricos para evidenciar o quanto as proposições eugenistas careciam de dados de realidade, sendo apenas resultado de opiniões sem fundamento.

${ }^{4}$ Magalhães Jr. (1981) observa que nas "Memórias póstumas de Brás Cubas”, obra publicada dois anos antes, basicamente a mesma sequência de frases de "A ideia do Ezequiel Maia" pode ser encontrada sob o título de "A ponta do nariz". 
Nesse sentido, esta análise permite passar em revista não só o pensamento de um médico oitocentista, pouco conhecido no cenário da história da psiquiatria, mas também aspectos da recepção do eugenismo no Brasil. Pois, se por um lado tais teorias foram abraçadas por intelectuais de viés racista, por outro foram, em Machado, objeto de aguda crítica. Ele considerava como equivocada a ideia de se classificar indivíduos e grupos por meio de medidas anatômicas reducionistas e, em função disso, designar aspectos do caráter humano. Daí sua alusão irônica à metafísica, indicando que um nariz metafísico é que daria conta de tal essencialização.

As considerações de Machado de Assis, que recorrentemente é criticado por uma suposta omissão frente às questões raciais da época, devem, portanto, ser entendidas dialogicamente. Sobretudo porque escreveu sua sátira com título de duplo sentido - O segredo do bonzo/mentiroso - a fim de desvelar o quanto a base científica do racismo era risível, posto que substanciada em opiniões voltadas para o aplauso das elites. E com destaque ao fato de que tanto um quanto o outro, o eugenismo e o aplauso, eram inconsistentes e superficiais.

\section{Referências}

Bakhtin, M. (2004). Marxismo e filosofia da linguagem. São Paulo: Hucitec.

Bué, A. (1872). Le nez, l'être dévoile par sa forme. Paris: Ghio.

Bué, A. (1880, 31 de dezembro). Relações physiologicas: physiognomonia. A Estação, IX(24), 261-262.

Bué, A. (1881, 15 de março). Revelações physiologicas: o nariz. A Estação, X(5), 50-51.

Bué, A. (1881, 15 de julho). Revelações physiologicas: o nariz. A Estação, X(13), 145-146.

Bué, A. (1894). Le magnétisme curatif: psycho-physiologie (hypnotisme, somnambulisme, fascination, suggestion mentale, clairvoyance, loi phénoménale de la vie). Paris: Chamuel éditeur.

Camargo Jr., K.R. (2007). A razão inconstante: ciência, saber e legitimação social. In A. Jacó-Vilela, \& L. Sato (Orgs.), Diálogos em Psicologia Social (pp. 17-34). Porto Alegre: Evangraf.

Editorial. (1879, 30 de dezembro). A Estação, VIII(24), p. 223.

Finn, M. (2009). Hysteria, Hypnotism, the Spirits, and Pornography: Fin-de-siècle Cultural Discourses in the Decadent Rachilde. Newark: University of Delaware Press.

França, E.M. (2007). Notas sobre a presença da sátira menipeia nas Memórias póstumas de Brás Cubas e no conto O segredo do bonzo. A Cor das Letras (UEFS), 8, 77-88.

Garnier, H. (1906). Como editor e proprietário. Boletim das Bibliothecas e Archivos Nacionaes, 5(1), 204-205. Recuperado de $<$ https://archive.org/details/ boletimdasbibli03nacigoog $>$. 


\section{HISTÓRIA DA PSIQUIATRIA}

Gould, S.J. (1991). A falsa medida do homem. São Paulo: Martins Fontes.

Losso, E.G.B. (2008). Nariz metafísico em O segredo do bonzo. In A.C. Secchin, J.M. Assis, D. Bastos, \& J.L. Jobim (Orgs.). Machado de Assis: novas perspectivas sobre a obra e o autor, no centenário de sua morte (pp. 114-129). Rio de Janeiro: Editora da Universidade Estadual do Rio de Janeiro.

Machado de Assis, J.M. (1990). Bons dias!: crônicas (1888-1889). São Paulo: Hucitec/ Editora da Unicamp.

Magalhães Jr., R. (1981). Vida e obra de Machado de Assis. 4 v. Rio de Janeiro: Civilização Brasileira.

Mansanera, A.R., \& Silva, L.C. (2000). A influência das ideias higienistas no desenvolvimento da psicologia no Brasil. Psicol. Estud., 5(1), 115-137.

Perez-Rincon, H. (2010, setembro). Literatura e psiquiatria. Rev. latinoam psicopatol. fundam., 13(3), 391-394.

Plas, R. (2012). Psychology and psychical research in France around the end of the 19th century. History of the Human Sciences, 25(2), 91-107.

Rego, E.S. (1989). O calundu e a panaceia. Machado de Assis, a sátira menipeia e a tradição luciânica. Rio de Janeiro: Forense Universitária.

Sterne, L. (1998). A vida e as opiniões do cavalheiro Tristram Shandy. São Paulo: Companhia das Letras.

Teixeira, I.P. (2008). Irônica invenção do mundo: uma leitura de O alienista. In M. L. Guidin, L. Granja, \& F. Ricieri (Orgs.), Machado de Assis: ensaios da crítica contemporânea. (pp. 109-142). São Paulo: Unesp.

Vicente, V.S. (2010). Os medalhões machadianos: a construção de um personagem. Dissertação de Mestrado, Instituto de Letras, Universidade Federal do Rio Grande do Sul, Porto Alegre, RS.

\section{Resumos}

(About noses extracted by Machado: racial eugenics, facial features and psychiatric theories in nineteenth-century Brazil)

The aim of this article was to analyze the dialogical relationship between Alphonse Bué's eugenics described in his work "Le nez, l'être dévoilé par sa forme" (1872) and the literary narrative of Machado de Assis, based on his short story "O segredo do Bonzo" (1882). According to the dialogical perspective of Mikhail Bakhtin, it was found that Machado criticized, through satires and parodies, the engenic bias of psychiatry which sought, by means of a supposed morphology of apelike features based on the nose, in the case of Alphonse Bué-, the etiology of social behavior.

Keywords: Eugenics, racism, Alphonse Bué, Machado de Assis 
(À propos de nez extraites par Machado: l'eugénisme racial, les traits du visage et des théories psychiatriques au Brésil du XIXe siècle)

L'objectif du présent article est d'analyser les rapports dialogiques entre l'eugénisme d'Alphonse Bué que l'on retrouve dans son œuvre "Le nez, l'être dévoile par sa forme» (1872) et le récit littéraire de Machado de Assis, à partir de son récit «O segredo do bonzo» (1882). Ainsi, selon la perspective dialogique de Mikhail Bakhtin, il a été constaté que Machado de Assis critiquait, au moyen de satires et de parodies, le biais eugénique de la psychiatrie qui cherchait établir, au travers d'une supposée morphologie de traits simiesques — basée sur le nez, dans le cas d'Alphonse Bué —. l'étiologie du comportement social.

Mots clés: Eugénisme, racisme, Alphonse Bue, Machado de Assis

(Acerca de narices extraídas por Machado: eugenesias raciales, rasgos faciales y teorías psiquiátricas en Brasil decimonónico)

El objetivo de este estudio fue analizar la relación dialógica entre la eugenesia de Alphonse Bué en "Le nez, l'être dévoile par sa forme” (1872) y la narración literaria de Machado de Assis desde el cuento "O segredo do Bonzo” (1882). Así, bajo la perspectiva dialógica de Mikhail Bakhtin, se encontró que Machado criticó, a través de sátiras y parodias, el sesgo eugenésico de la psiquiatría que buscaba una supuesta morfología de rasgos simiescos - basándose en la nariz, en el caso de Alphonse Bué - la etiología de la conducta social.

Palabras clave: Eugenesia; racismo; Alphonse Bué; Machado de Assis

Palabras clave: La eugenesia, el racismo, Alphonse Bue, Machado de Assis

(Über Nasen, extrahiert von Machado: rassistische Eugenik, Gesichtszüge und psychiatrische Theorien im Brasilien des neunzehnten Jahrhunderts)

Ziel dieses Artikels ist es, die dialogische Beziehung zwischen der Eugenik von Alphonse Bué in „Le nez, l'être dévoilé par sa forme“ (1872) und dem literarischen Erzählungsstil von Machado de Assis zu untersuchen, anhand seiner Kurzgeschichte „, $O$ segredo do bonzo " (1882). Aufgrund der dialogischen Perspektive von Mikhail Bakhtin stellt man fest, dass Machado de Assis in seinen Satiren und Parodien die eugenische Psychiatrie kritisiert, welche mittels einer Morphologie affenähnlicher Merkmale — die zum Beispiel auf die Nase beruhte, wie im Falle von Alphonse Bué — die Ätiologie des Sozialverhaltens zu erklären versuchte.

Schlüsselwörter: Eugenik, Rassismus, Alphonse Bue, Machado de Assis

(马查多的鼻子：种族优生学，面部特征和巴西19世纪的精神分析的理论）

这项研究的目的是分析阿方索·布埃的1872年作品“鼻子--存在型式的显示”和 巴西文学作家马查多.德阿西斯(Machado de Assis)的1882年发表的短篇小说“朋左 


\section{HISTÓRIA DA PSIQUIATRIA}

的秘密”之间的有关优生学的对话关系。根据米哈伊尔·巴赫金的观念, 我们发现马 查多.德阿西斯通过讽刺和模仿的笔法批评了种族优生学思想, 这种优生观点基于 对类人猿的鼻子的特征的研究, 是阿方索. 布埃的社会行为的起因论的基本观点。 关键词: 优生学, 种族主义, 阿方斯 - 布埃, 马查多.德阿西斯

Citação/Citation: Castro, A. de C. (2015, junho). De narizes extraídos por Machado: eugenias raciais, traços faciais e teorias psiquiátricas no Brasil oitocentista. Revista Latinoamericana de Psicopatologia Fundamental, 18(2), 339-351.

Editores do artigo/Editores: Profa. Dra. Ana Maria G. Raimundo Oda e Prof. Dr. Paulo Dalgalarrondo.

Recebido/Received: 8.2.2015/2.8.2015 Aceito/Accepted: 5.3.2015 / 3.5.2015

Copyright: (C) 2009 Associação Universitária de Pesquisa em Psicopatologia Fundamental/ University Association for Research in Fundamental Psychopathology. Este é um artigo de livre acesso, que permite uso irrestrito, distribuição e reprodução em qualquer meio, desde que o autor e a fonte sejam citados / This is an open-access article, which permits unrestricted use, distribution, and reproduction in any medium, provided the original authors and sources are credited.

Financiamento/Funding: Esta pesquisa é financiada pelo Conselho Nacional de Desenvolvimento Científico e Tecnológico - CNPq (Brasília, DF, Br) / This research is funded by the Conselho Nacional de Desenvolvimento Científico e Tecnológico - CNPq (Brasília, DF, Br)

Conflito de interesses/Conflict of interest: $\mathrm{O}$ autor declara que não há conflito de interesses / The author has no conflict of interest to declare.

\section{Alexandre de Carvalho Castro}

Doutor em Psicologia Social pela Universidade do Estado do Rio de Janeiro - UERJ (Rio de Janeiro, RJ, Br); Docente no Centro Federal de Educação Tecnológica Celso Suckow da Fonseca (Rio de Janeiro, RJ. Br).

Rua Uruguai, 413/706 - Tijuca

20510-060 Rio de Janeiro, RJ, Br

e-mail: o.aken@uol.com.br 